Textures and Microstructures, 1989, Vol. 10, pp. 325-346

Reprints available directly from the publisher

Photocopying permitted by license only

(C) 1989 Gordon and Breach Science Publishers Inc.

Printed in the United Kingdom

\title{
Neutron Diffraction Texture Analysis of Multi-Phase Systems
}

\author{
H.-G. BROKMEIER \\ Department of Physical Metallurgy, TU Clausthal and GKSS-Research Center, \\ Geesthacht GmbH, FRG
}

(Received 23 February, 1989; in final form 23 March, 1989)

\begin{abstract}
Neutron diffraction methods for texture analysis are closely parallel to well-known $\mathrm{X}$-ray diffraction techniques. The chief advantage of neutron diffraction over X-ray diffraction, however, arises from the fact that the interaction of neutrons with matter is relatively weak, and consequently the penetration depth of neutrons is $10^{2}-10^{3}$ times larger than that of X-rays. Hence neutron diffraction is an efficient tool for measuring textures in multi-phase systems. Based on the high transmission of a neutron beam the effect of anisotropic absorption in multi-phase materials can be neglected in most cases. Moreover, the analysis of bulk textures becomes possible, such that textures in a wide variety of multi-phase systems can be studied which are of special interest in engineering and science (metals, alloys, composites, ceramics and geological specimens).
\end{abstract}

KEY WORDS: Neutron diffraction, texture analysis, ceramics, composites, rocks.

\section{INTRODUCTION}

In recent developments new multi-phase materials with special properties are being tested for extreme applications (high temperatures, high strength, extreme low density etc.). Such materials are among others: composites (metal-matrix composites, ceramicceramic composites etc.), multi-phase intermetallic compounds (Al-Ti, Al-Si, Al-Ti-Si etc.) and ceramic materials. Together with the microstructure of a material, polycrystalline samples are charac- 
terized by their texture-the distribution function of the crystallographic orientations of the grains in relation to a sample coordinate system. Therefore, phase analysis and texture analysis have an esssential contribution to make in the investigation of new materials in applied as well as in scientific research. Moreover, numerous standard samples are multi-phase with unknown texture and unknown anisotropic porperties (ceramics, rocks, polyphase steels etc.).

The texture of a single-phase material is defined as (see Bunge, 1982):

$$
\frac{d V / V}{d g}=f(g) ; \quad g=\{\alpha, \beta, \gamma\}=\left\{\varphi_{1}, \phi, \varphi_{2}\right\}
$$

$f(g)$-orientation distribution function (ODF)

$d V / V$-volume fraction of the crystallites with the orientation $g$ $d g$-orientation element

In the case of a multi-phase material each phase has its own texture. Therefore, the complete texture of a multi-phase material consists of the individual textures of all components $i$ and of the correlations between these textures. Figure 1 shows the microstructure of a two-phase sample. Hence, the general description of the

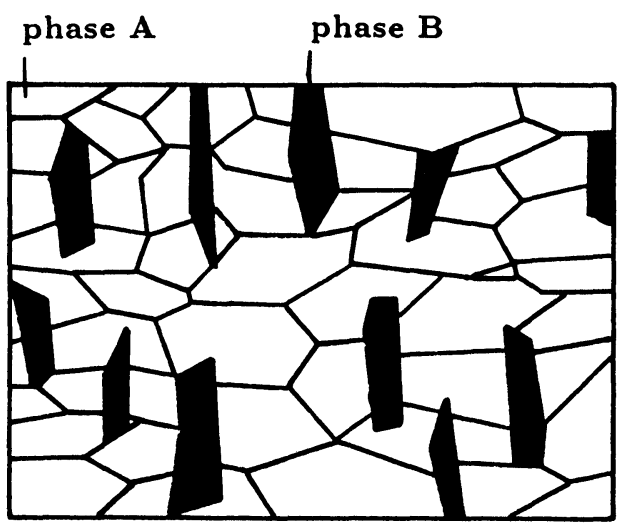

Figure 1 Theoretical microstructure of a two-phase material. 
ODF becomes:

$$
\frac{d V^{i} / V^{i}}{d g}=f^{i}(g) ; \quad g=\{\alpha, \beta, \gamma\}=\left\{\varphi_{1}, \phi, \varphi_{2}\right\}
$$

Here $f^{i}(g)$ is the orientation distribution function of the phase $i$ in the multi-phase material. Based on the complex composition of a multi-phase material, texture analysis becomes much more complicated and time consuming than for single-phase materials such as aluminium or copper sheets. Hence, neutron diffraction can be more than an alternative to standard X-ray techniques for analysing the texture of polycrystalline multi-phase material.

\section{NEUTRON DIFFRACTION}

Nearly 20 years after the discovery of the neutron by Chadwick (1923), the first neutron diffraction texture measurement was carried out by Brockhouse (1953). As a consequence of the behaviour of the neutrons when interacting with matter (see e.g. Bacon, 1975), neutron diffraction becomes an additional diffraction technique, for example to X-ray or electron diffraction. Today, neutron diffraction is a standard method in investigations in physical, chemical, material, and geological research.

Looking at the different standard techniques using X-ray diffraction to measure textures, in most cases there is a similar neutron technique. Comparison between $\mathrm{X}$-ray and neutron diffraction texture measurements has been made by various authors (e.g. Kleinstück et al., 1976; Szpunar, 1976; Welch, 1986). Only some essential points will be summarized here. For detailed information reference should be made to one of the above overviews. The penetration depth $d_{1 / 2}$ for most materials in neutron diffraction is a factor of $10^{2}-10^{3}$ higher than for X-ray diffraction (see Table 1). $d_{1 / 2}$ represents the specimen thickness at which the primary intensity of the incoming beam is reduced by $50 \%$.

Thus neutron diffraction is an efficient tool for bulk texture determination and for analysing coarse grained materials. Moreover, the neutron scattering length $b$ is independent of the scattering angle $2 \theta$, while the X-ray scattering length $f_{x}$ depends on the scattering angle. A $2 \theta$-diagram measured with neutrons often 
Table 1 Penetration depth $d_{1 / 2}$ of some metals (X-ray and neutron scattering)

\begin{tabular}{lll}
\hline Metal & $\begin{array}{l}d_{1 / 2} \text { in } \mu \mathrm{m} \\
(\mathrm{X} \text {-ray } 0.154 \mathrm{~nm})\end{array}$ & $\begin{array}{l}d_{1 / 2} \text { in } \mu \mathrm{m} \\
(n \text {-rays } 0.150 \mathrm{~nm})\end{array}$ \\
\hline $\mathrm{Fe}$ & $3.0 \times 10^{1}$ & $5.0 \times 10^{3}$ \\
$\mathrm{Al}$ & $5.3 \times 10^{2}$ & $6.3 \times 10^{4}$ \\
$\mathrm{Cu}$ & $1.5 \times 10^{2}$ & $8.0 \times 10^{3}$ \\
$\mathrm{~Pb}$ & $2.0 \times 10^{1}$ & $2.3 \times 10^{4}$ \\
\hline
\end{tabular}

shows more Bragg-lines than an equivalent X-ray measurement. Especially in low symmetry and in multi-phase materials, a line-rich powder pattern is preferable in order to obtain a sufficient number of pole figures of high quality for a pole figure inversion.

\section{NEUTRON DIFFRACTION TEXTURE MEASUREMENT OF A SINGLE-PHASE SAMPLE}

In general, there are two different methods for measuring the texture of a polycrystalline single-phase sample:

1) The orientation of each grain is measured individually (single grain method). Based on a statistical number of about 500 grains necessary for an analysis, this technique is very time consuming. Moreover, the analysis of single grains using neutron diffraction sets a lower limit on the grain size in the $\mathrm{mm}$ range to get sufficient scattered intensity. The single grain method with neutron diffraction was first described by Smyth, Vergamini and Schultz (1988) and is usable only in special applications.

2) The texture is measured with numerous grains in a selected volume of the sample at the same time (volume method). Depending on the transmission properties of the neutron beam, the volume selected can be the whole sample up to some $\mathrm{cm}$ in diameter or a discrete volume within the compact sample down to some $\mathrm{mm}$ in diameter. In contrast to the single grain method, the volume method is time saving. Just as in X-ray diffraction, the volume method is the standard technique in neutron diffraction texture analysis of a polycrystalline sample. 


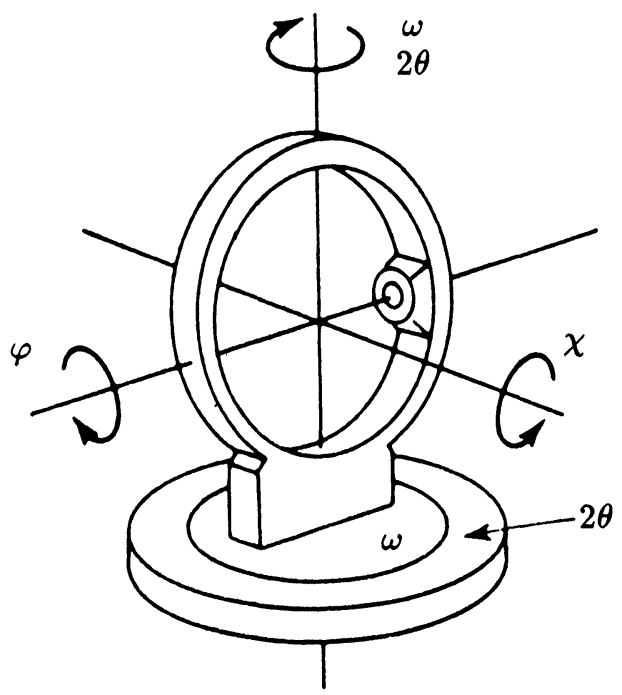

Figure 2 Principal axes of a four-circle diffractometer.

A calcite measurement illustrates the standard technique of a neutron diffraction texture measurement of a single-phase material. Calcite, $\mathrm{CaCO}_{3}$, is a mineral which crystallizes in a trigonal space group $R \overline{3}_{c}$. The texture measurement is performed on a standard four-circle diffractometer. The principal axes are shown in Figure 2. $2 \theta$ is twice the Bragg angle $\theta$ which corresponds to the crystallography of the material. The $\omega$ axis is coincident with the $2 \theta$ axis and defines the angle between the diffraction vector and the plane of the $\chi$ circle. The two angles $(\omega, 2 \theta)$ are also used for standard powder diffraction work (two-circle diffractometer). Hence, the other two angles $\chi$ and $\varphi$ correspond to the pole figure angles $\alpha$ and $\beta$ (see Bunge, 1986a) and are used for the pole figure measurement described later on. The sample is positioned in the center of the diffractometer.

Before the pole figures can be measured, the $2 \theta$ positions of the Bragg-reflections must be determined, a selection of the suitable Bragg-reflections for a pole figure measurement has to be made, and a selection of the background positions is necessary. These 


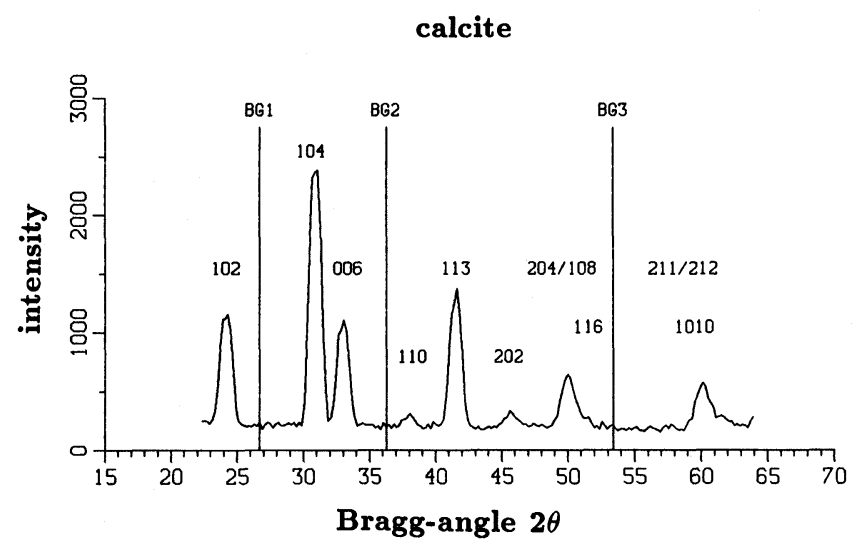

Figure $32 \theta$-diagram of calcite.

preliminary steps involve:

1) Calculation using structural data (e.g. JCPDS 5-586)

2) Measurement of a powder pattern using X-ray diffraction and transformation to neutron diffraction

3) Measurement of a $2 \theta$-diagram with neutron diffraction

In Figure 3, the $2 \theta$-diagram of the calcite sample is shown (see Wenk et al., 1988). The calcite measurement was performed at TEX-1, the neutron texture diffractometer at GKSS Research Center. A detailed description of TEX-1 has been given by Brokmeier et al. (1987). The wavelength used was $\lambda=0.161 \mathrm{~nm}$. With a neutron flux of $8 \times 10^{4} \mathrm{n} / \mathrm{cm}^{2} \mathrm{~s}$, a step width of $0.2^{\circ}$ in $2 \theta$, and a ${ }^{3} \mathrm{He}$-single detector, such a measurement requires a time of $3.5 \mathrm{~h}$. In contrast to normal powder diffraction for high resolution work such as crystal structure determination or phase analysis, typical parameters for a texture analysis were chosen. The detector slit was completely open and the whole cross section of the detector with $25 \mathrm{~mm}$ in diameter was active. To give up a collimation of the incoming beam as well as of the scattered beam an enlargement of the pole figure window and a reduction of the counting time was obtained. But on the other hand, the Bragg-lines are broader than in high resolution work. 
The calcite diagram shows six separate Bragg-reflections and some overlapping lines. For the pole figure measurement of the calcite, the six separate Bragg-lines "(012), (104), (006), (110), (113) and (202)" and the three background positions "BG1, BG2, BG3" were chosen. Each pole figure measurement was carried out with a fixed detector position $2 \theta$ and a fixed $\omega$ value (half of the Bragg-angle $2 \theta$ ) given by the $2 \theta$-diagram. The diffraction diagram, Figure 3 , shows also the difference in the reflectivity of the different Bragg-reflections. Therefore, the counting time for the (202) pole figure measurement had to be longer than that for the (006) measurement.

Subsequently to the determination of the $2 \theta$-diagram, the pole figure measurements as well as the background measurements were carried out by one of the standard scanning routines (see e.g. Welch, 1986; Höfler, 1986) one after the other. For example, Figure 4 shows the (006) pole figure and the background BG3. An equal angular scanning routine with 1368 points was chosen $\left(\Delta \varphi=5.0^{\circ}\right.$ and $\Delta \chi=5.0^{\circ}$ ). The set of six pole figures (trigonal structure) was sufficient to calculate the orientation distribution function (ODF) and to describe the anisotropy of this calcite sample.

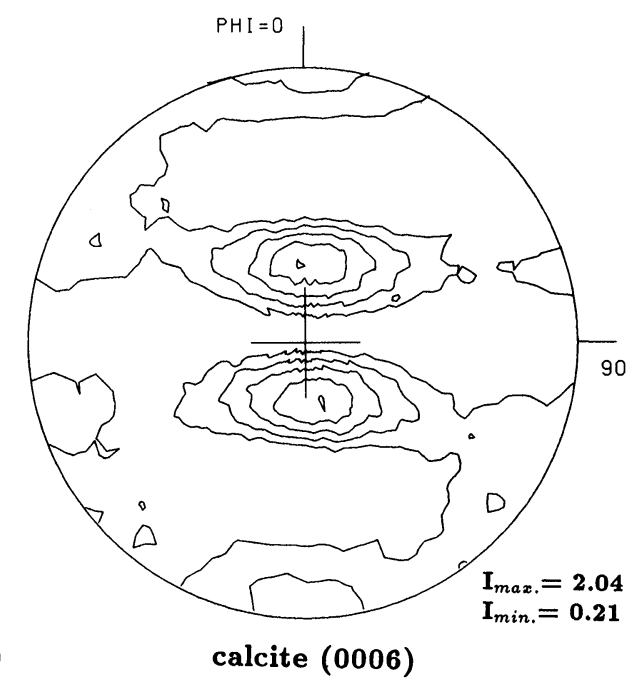

Figure 4 (a) Calcite pole figure of (0006) at the position BG3 of Figure 3. 


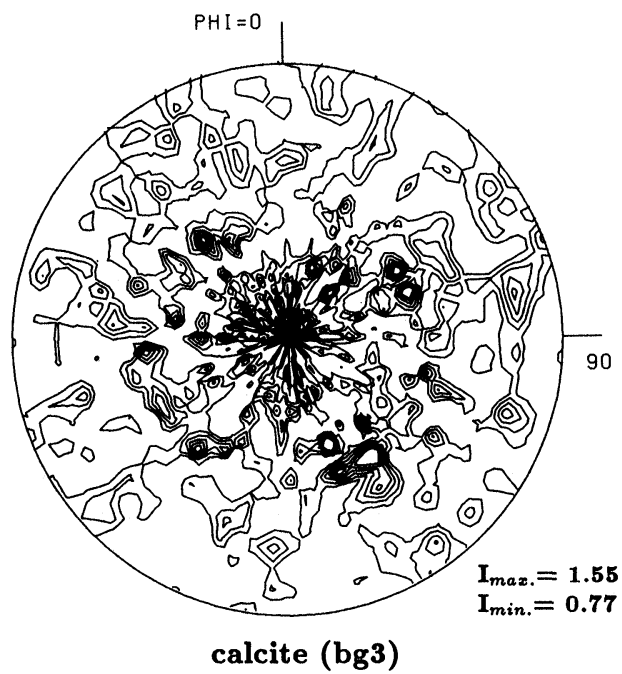

Figure 4 (b) Calcite background pole figure at the position BG3 of Figure 3.

\section{NEUTRON DIFFRACTION TEXTURE MEASUREMENT OF A MULTI-PHASE SAMPLE}

A complete texture analysis of a multi-phase polycrystalline material consists of the texture determination of all components of the sample. Depending on the system studied, this leads to an increase of the requirements on the analysing techniques.

The procedure in texture measurement of multi-phase materials using the volume method also starts with an analysis of the $2 \theta$-diagram as in single-phase materials. In addition to the selection of suitable Bragg-reflections and background positions, a phase analysis-determination of the composition of the sample-is necessary. Looking at the different systems of diffraction patterns four types can be distinguished:

1) A $2 \theta$-diagram only with separate Bragg-reflections

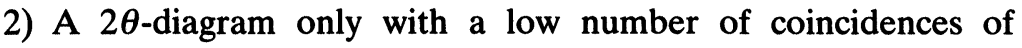
Bragg-reflections 
3) A complicated $2 \theta$-diagram with a frequent partial overlap of Bragg-reflections

4) A more complicated $2 \theta$-diagram with a frequent partial and total overlap of Bragg-reflections

Depending on the type of diffraction patterns the experimental conditions and the evaluation procedure have to be adjusted.

Extruded $\mathrm{Al}-\mathrm{Pb}$ composites provide an example of the first type of diffraction pattern. The $2 \theta$-diagram of an $\mathrm{Al}-\mathrm{Pb}$ composite with $50 \mathrm{Vol} . \% \mathrm{Al}$ and $50 \mathrm{Vol} . \% \mathrm{~Pb}$ is shown in Figure 5. This measurement was performed at the same neutron diffractometer (TEX-1), and with the same experimental conditions as used before to measure the calcite pole figures. Only the counting time had to be increased as a consequence of the lower volume fractions of the measured components and of the different reflectivities. If we compare the $2 \theta$-diagram of the two-phase composite with the $2 \theta$-diagram of the single-phase calcite both diagrams bear some similarities. In both cases, the diagram contains six separate Bragg-reflections. Both $\mathrm{Al}$ and $\mathrm{Pb}$ crystallize in the cubic space group Fm3m, so that for both metals three Bragg-reflections "Al(111), (200), (220); Pb(111), (200), (220)" could be measured which are sufficient for a pole figure inversion. In practice, there is

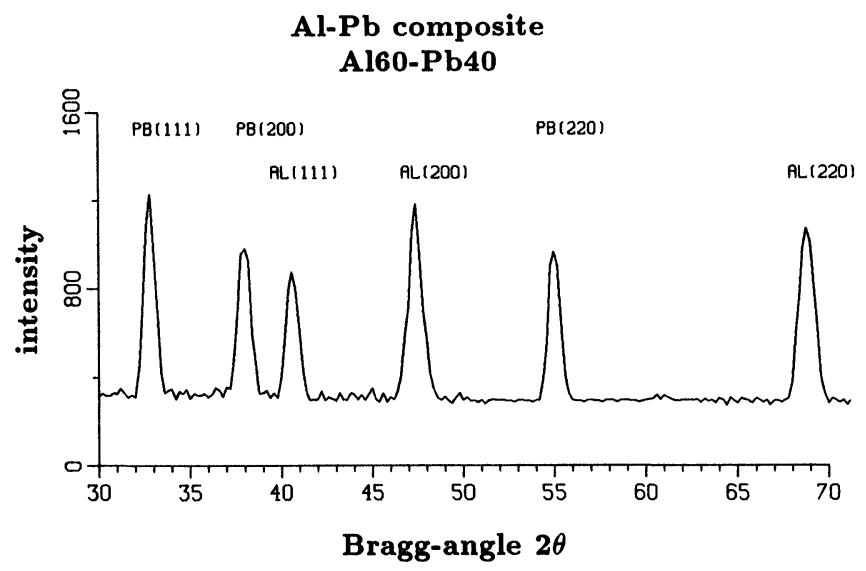

Figure $52 \theta$-diagram of an $\mathrm{Al}-\mathrm{Pb}$ composite. 
no essential difference between the texture measurement of the single-phase calcite and the two-phase cubic-cubic $\mathrm{Al}-\mathrm{Pb}$ composite. For each pole figure measurement the ${ }^{3} \mathrm{He}$ single detector was positioned at the corresponding Bragg-angle in the same way as for the pole figure measurement of the single-phase calcite sample described before. Using a standard scanning routine, the three $\mathrm{Al}$-pole figures, the three $\mathrm{Pb}$-pole figures, and the background measurements, respectively, were measured one after the other.

Thereafter the inverse pole figures were calculated and plotted to explain the two textures of the composite, see Figure 6. an interdependence of two textures on the internal deformation degree of the fibres was established. a detailed description of the investigations of a series of extruded $\mathrm{Al}-\mathrm{Pb}$ composites with different compositions was given by Brokmeier, Böcker and Bunge (1988).

Composites are also obtained in system $\mathrm{Al}-\mathrm{Cu}$ using powder compaction followed by cold extrusion. Both metals are also cubic
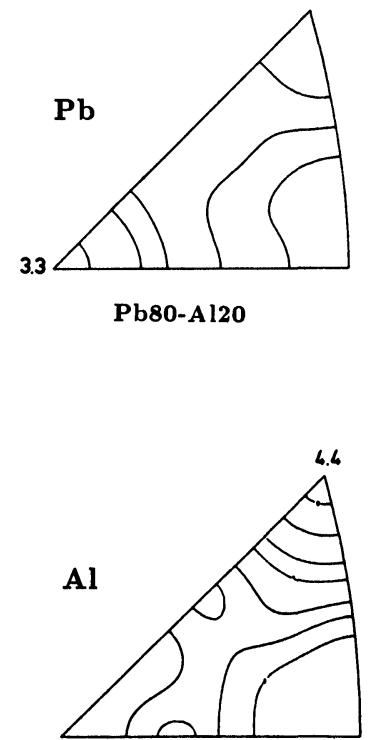

Al80-Pb20

Figure 6 Inverse pole figures of $\mathrm{Pb}$ in an $\mathrm{Al} 20-\mathrm{Pb} 80$ composite and of $\mathrm{Al}$ in an Al80-Pb20 composite. 


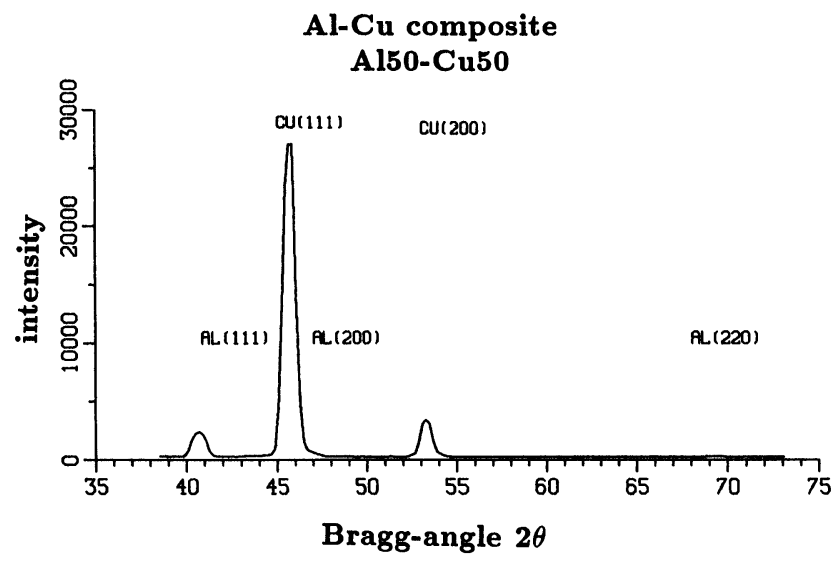

Figure $72 \theta$-diagram of an $\mathrm{Al}-\mathrm{Cu}$ composite.

as in the system discussed before, but the $2 \theta$-diagram shows a partial overlap of two reflections and thus represents the second type of pattern. Figure 7 shows a part of the $2 \theta$-diagram containing the coincidence of $\mathrm{Al}(200)$ with $\mathrm{Cu}(111)$. This measurement was also performed at TEX-1 using the same apparative parameters as before. If it is possible to measure enough separate Braggreflections for an ODF calculation, these two overlapping reflections can be neglected, and the same procedure as in the case of $\mathrm{Al}-\mathrm{Pb}$ composites can be used. However, normally neutron diffractometers have a limited $2 \theta$-range, due to the massive shielding, and therefore only a limited number of Bragg-reflections can be measured. Moreover, with the instrument TEX-1 the take-off angle of the monochromatic beam is fixed, and a change in wavelength can only be achieved by changing the monochromator material. Hence, these conditions only allow the $\mathrm{Al}(111)$, (200), (220) and $\mathrm{Cu}(111),(200)$, to be measured, so that all Braggreflections including the overlapping ones had to be measured and to be used for the texture analysis.

The pole figure measurements of the three Al-reflections "(111), (200), (220)," the two Cu-reflections "(111), (200)" and the necessary background measurements were carried out in the same way as for the $\mathrm{Al}-\mathrm{Pb}$ composites. All measurements were made one 
after the other. With some modifications (see Dahms et al. 1988) ODF-analysis can also be carried out in two phases simultaneously including overlapping pole figures. This method was used to calculate the two inverse pole figures of $\mathrm{Al}$ and $\mathrm{Cu}$ respectively. After cold extrusion both phases develop a $\langle 111\rangle$ fibre texture. The degree of preferred orientation depends strongly on the composition of the composite and the degree of the deformation (see Brokmeier et al., 1988).

The two examples of multi-phase materials shown above belonged to type 1 and 2 where the differences to single-phase materials are relatively low, and nearly the same experimental methods of texture analysis can be used as in single-phase materials and only a small modification of the subsequent evaluation routines are necessary. Texture determination in materials belonging to type 3 and 4 is quite different. It requires the development of some new techniques in the experimental method as well as in data evaluation.

If the crystal symmetry is low and/or the number of components of a multi-phase material increases, line-rich diffraction patterns are to be expected. Table 2 shows some examples of some common materials. The data were obtained using the JCPDS-files (JCPDSJoint Committee on Powder Diffraction Standards), see column 4.

The number of Bragg-reflections within a $2 \theta$-range of $80^{\circ}$ $(\lambda=0.25 \mathrm{~nm})$ depends on the crystal symmetry and the number of phases. This strong influence can be seen by comparing the

Table 2 Number of Bragg-reflections of some common materials $\left(\leq 80^{\circ}\right.$ in $\left.2 \theta ; \lambda=0.25 \mathrm{~nm} ; d_{\min }=0.1944 \mathrm{~nm}\right)$

\begin{tabular}{llll}
\hline Material & Phase composition & $\begin{array}{l}\text { Number of } \\
\text { reflections }\end{array}$ & JCPDS \\
\hline $\begin{array}{l}\text { aluminium } \\
\text { calcite }\end{array}$ & $\begin{array}{l}\text { single-phase } \\
\text { single-phase }\end{array}$ & 2 & $04-0787$ \\
$\mathrm{Al} / \mathrm{Pb}$ & $\begin{array}{l}\text { two-phase } \\
\text { composite } \\
\text { two-phase }\end{array}$ & 4 & $05-0586$ \\
$\mathrm{Al} / \mathrm{Al}_{2} \mathrm{O}_{3}$ & $\begin{array}{l}\text { composite } \\
\text { two-phase }\end{array}$ & 8 & $04-0787$ \\
$\mathrm{TiAl}-\mathrm{Ti}_{3} \mathrm{Al}$ & $\begin{array}{l}\text { two-0686 } \\
\text { intermetallic } \\
\text { three-phase rock }\end{array}$ & 10 & $04-0787$ \\
& $\begin{array}{l}\text {-olivine } \\
\text {-orthoenstatite } \\
\text {-clinoenstatite }\end{array}$ & 76 & $05-0173$ \\
& & $14-0451$ \\
& & $20-1139$ \\
& & $19-0768$ \\
& & & $19-0769$ \\
\hline
\end{tabular}




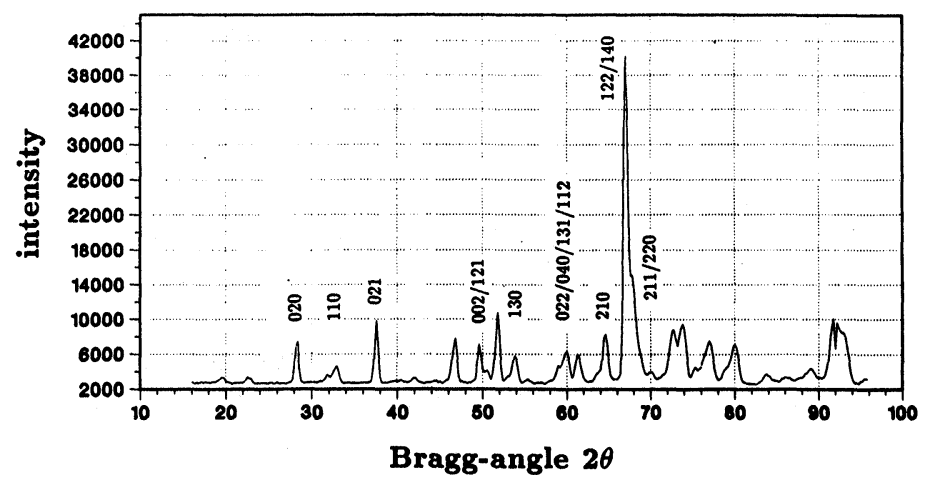

Figure $82 \theta$-diagram of a lherzolithe, some of the olivine reflections are marked.

single-phase aluminium with 2 Bragg-reflections with the two-phase $\mathrm{TiAl}-\mathrm{Ti}_{3} \mathrm{Al}$ intermetallic compound with $10 \mathrm{Bragg}$-reflections and with the three-phase lherzolithe with 76 Bragg-reflections. Figure 8 shows the neutron diffractogram of a lherzolithe sample. This measurement was performed at the Institute Max von Laue-Paul Langevin (ILL) in Grenoble using the diffractometer D1B. Lherzolithe is a natural rock composed of olivine, orthopyroxene, clinopyroxene and some accessory minerals such as spinel and serpentine minerals. In contrast to the diagrams shown before (Figures 2,5 and 7) the diagram is extremely line-rich. Looking at such a sample with such a high number of Bragg-reflections a new philosopy for texture measurement is necessary. A large number of partially and totally overlapping Bragg-reflections of the same mineral and of different minerals is seen. Therefore quantitative texture analysis has to be performed in three steps:

1) Optimization of the experimental conditions

2) Introduction of the peak profile analysis into texture analysis

3) Pole figure inversion with overlapping pole figures

Firstly the experimental conditions for texture measurements of samples with line-rich diffraction patterns have to be carefully selected. This means the highest possible resolving in $2 \theta$ is desirable. Therefore, the neutron wavelength must be chosen in such a way, that on the one hand a sufficient number of Bragg- 
Table 3 Number of Bragg-reflections for different wavelength $\left(\leq 80^{\circ}\right.$ in $\left.2 \theta\right)$

\begin{tabular}{lcccc}
\hline Material & $\lambda=0.12 \mathrm{~nm}$ & $\lambda=0.16 \mathrm{~nm}$ & $\lambda=0.20 \mathrm{~nm}$ & $\lambda=0.25 \mathrm{~nm}$ \\
\hline aluminium & 6 & 3 & 2 & 2 \\
calcite & 44 & 23 & 12 & 6 \\
$\mathrm{Al} / \mathrm{Al}_{2} \mathrm{O}_{3}$ & 40 & 18 & 10 & 8 \\
TiAl-Ti ${ }_{3} \mathrm{Al}$ & 33 & 21 & 13 & 10 \\
lherzolithe & 234 & 171 & 116 & 76 \\
\hline
\end{tabular}

reflections for a pole figure inversion (see Wagner and Esling, 1986) can be measured and on the other hand an optimum separation of the overlapping reflections is obtained. Table 3 shows some examples of the influence of the wavelength on the number of Bragg-reflections.

Thus, it is no longer possible to measure complete textures by using a neutron diffractometer equipped only with a single detector. The occurrence of overlapping reflections requires measurement of the whole $2 \theta$-range simultaneously. Figure 9 for example shows the partial overlapping of $\mathrm{Al}(200)$ and $\mathrm{Cu}(111)$ in an $\mathrm{Al}-\mathrm{Cu}$ fibre

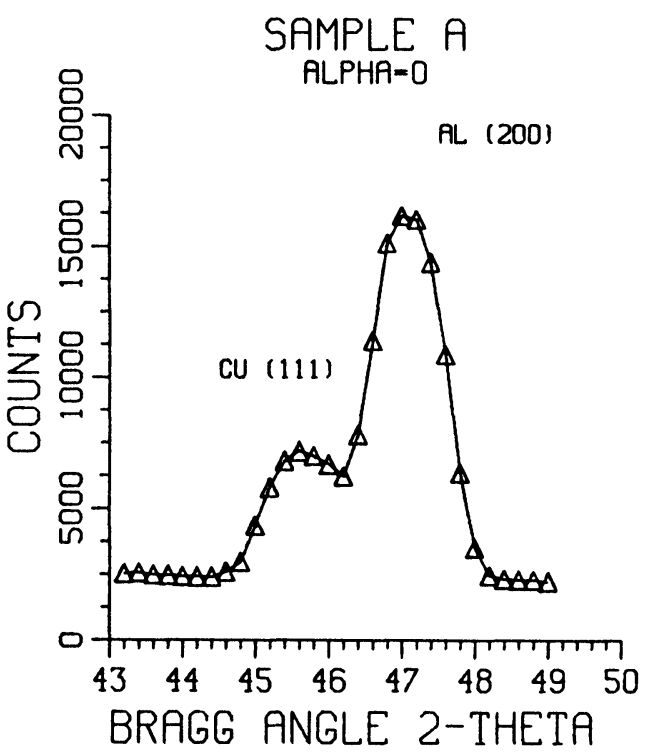

Figure 9 Partial overlapping of $\mathrm{Al}(200)$ and $\mathrm{Cu}$ (111) in an $\mathrm{Al}-\mathrm{Cu}$ composite sample. 
composite. In order to separate these two reflections, similar $2 \theta$ spectra over a range of 6 degrees have to be measured for all pole figure points. In the case of lherzolithe a $2 \theta$-range of nearly 40 degrees for $\lambda=0.12 \mathrm{~nm}$ or nearly 80 degrees for $\lambda=0.25 \mathrm{~nm}$ has to be measured simultaneously for any pole figure point.

In contrast to X-ray diffraction, the use of linear position sensitive detectors (Convert and Forsyth, 1983) in neutron powder diffractometry is standard and is well introduced. Therefore the new generation of neutron texture diffractometers for the analysis of line-rich materials consist of a combination of a standard four-circle diffractometer (single crystal work) and a linear position sensitive detector (powder diffraction work). A linear position sensitive detector is very time-saving and gives much more information than a single detector. Within the complete $2 \theta$-range, to be measured, the integral intensities of all Bragg-reflections can thus be obtained and additionally higher accuracy of the background measurement is also possible. Furthermore, new computer programs have to be installed in order to handle the larger amounts of experimental data, to measure with new scanning routines and to offer an increase in computer time as well as in memory space.

When using a linear position sensitive detector the diffraction vector of only one of the pole figures lies in the plane of the $\chi$ rotation of the Eulerian cradle. Hence, only this pole figure is scanned completely by conventional scanning routines. All other pole figures are only obtained in an incomplete range, leaving a "dead area" in the center, as was shown by Bunge, Wenk and Pannetier (1982). This is illustrated in Figure 10. In contrast to the commonly used equal angular scanning routine, the time-saving equal area scan (decrease of pole figure points) was used here. The "dead areas" in the pole figure center can be filled up by interpolation or, better, by additional measurements with different $\omega$-values. A subsequent transformation of the angles $\chi$ and $\varphi$ of the Eulerian cradle to the pole figure angles $\alpha$ and $\beta$, which takes $\Delta \omega$ into account is then necessary.

$$
\begin{gathered}
\cos \alpha=\cos (\Delta \omega-\omega) \cos \chi \\
\sin \beta_{0}=\cos (\Delta \omega-\omega) \sin \chi /(\sin \alpha) \\
\beta=\beta_{0}+\varphi
\end{gathered}
$$



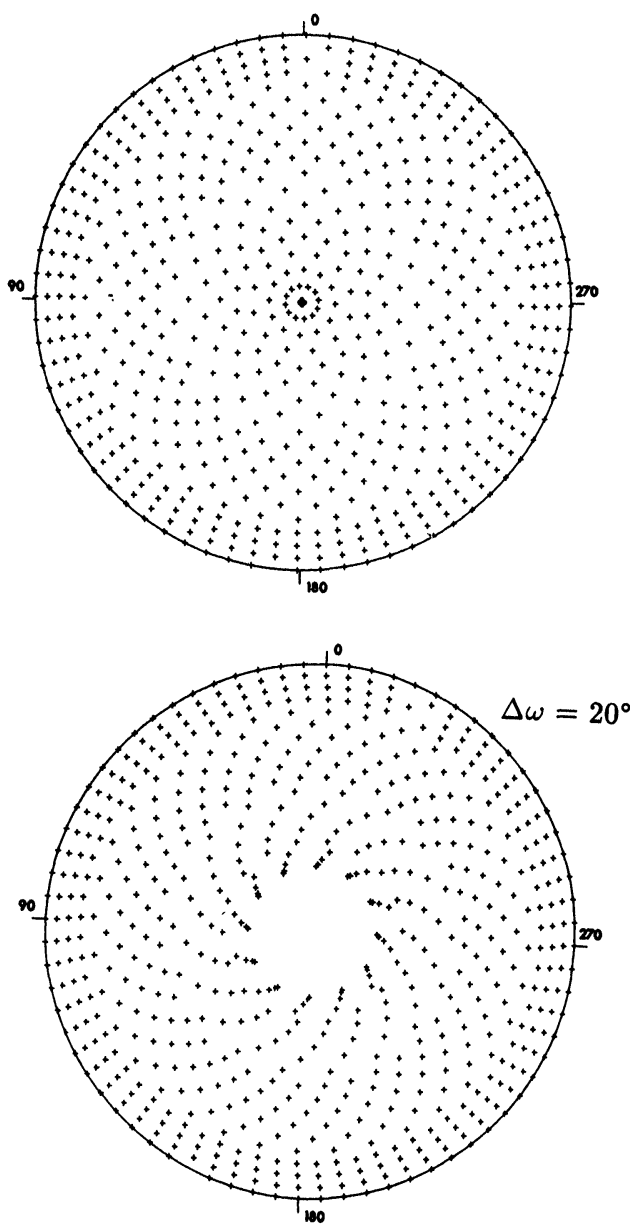

Figure 10 Net of pole figure points of an equal area scan for the one complete pole figure $\left(\Delta \omega=0^{\circ}\right)$ and for $\Delta \omega=20^{\circ}$ using a linear position sensitive detector.

As an example the olivine (020) pole figure is shown in Figure 11. The projection plane is parallel to the foliation and the lineation crosses the pole figure from left to right as marked.

One way to separate partly overlapped reflections is to carry out a peak profile analysis as described by different authors (Jansen, Schäfer, Will, 1986; Antoniadis, Berruyer, Filhol, 1987). Pole figure 


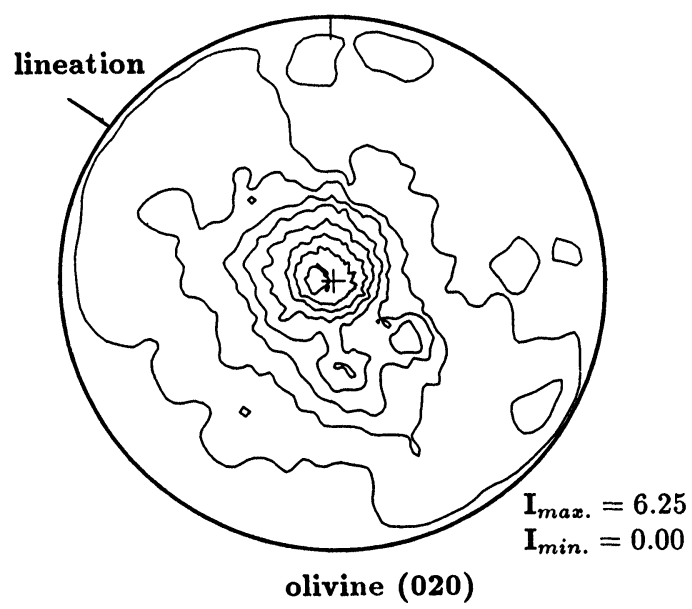

Figure 11 Olivine (020) pole figure measured at D1B ILL-Grenoble.

measurement using a linear position sensitive detector consists of the measurement of a large number of diffraction patterns with different sample orientations. For each of these diffraction patterns the peak profile analysis has to be carried out. Figure 12 shows an example of the peak separation of two feldspar lines. Of course, the

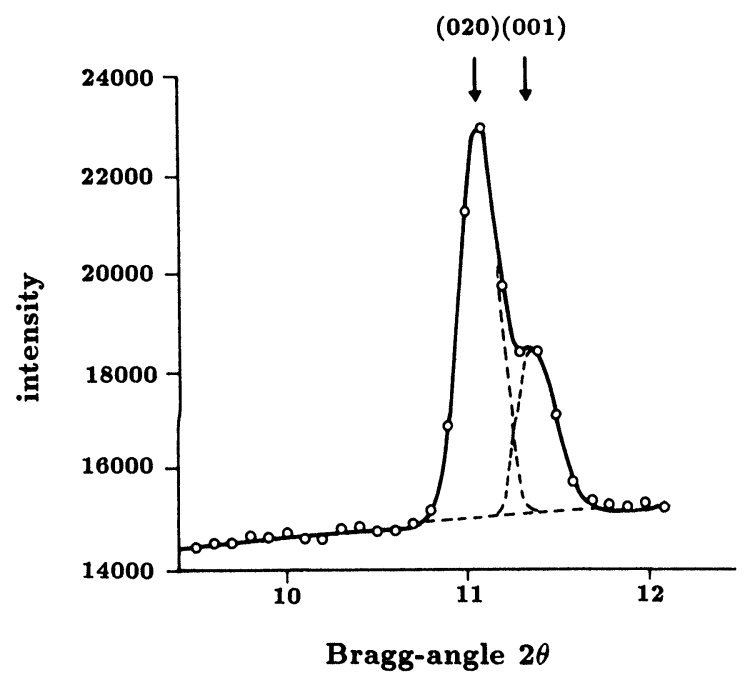

Figure 12 Peak separation by peak profile analysis in case of two overlapping feldspar reflections. 


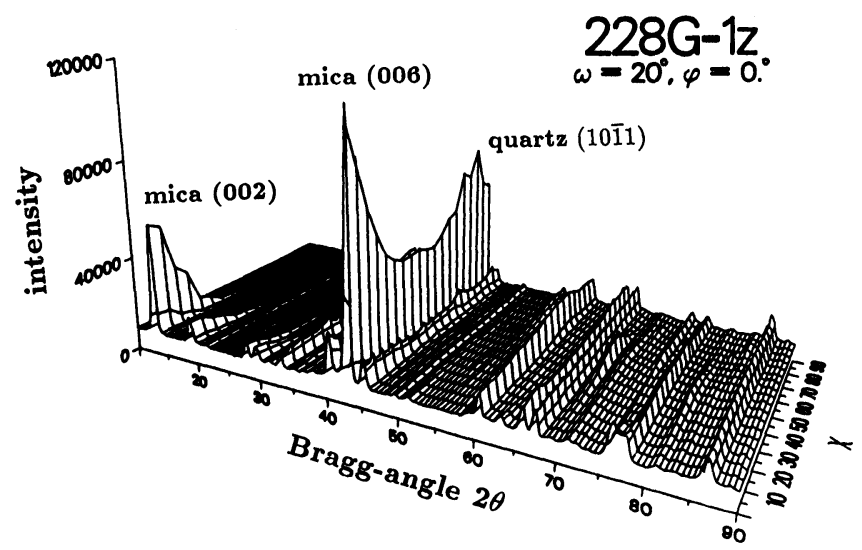

Figure 13 Set of diffraction patterns of paragneiss showing separation of the overlapping reflections of mica (006) and quartz (1011) in the orientation space.

evaluation time will be strongly increased if a peak profile analysis is necessary. A description of peak profile analysis and especially the introduction of this technique to textural research will be given by Will (1989). The application of peak profile analysis is limited to partial overlap of pole figures. In the case of total overlap such as in the (003) and the (201) reflections of the hexagonal intermetallic compound $\mathrm{Al}_{3} \mathrm{Ni}_{2}$ the method does not work.

Another possibility for peak separation is the calculation of the orientation distribution function from totally or partially coincident pole figures (Dahms, Bunge 1987). This "crystallographic" separation is possible for totally overlapping reflections with different hkl-values of the same phase or of different phases of a multi-phase material.

In Figure 13 an example of total overlapping of the reflections of two different phases is shown. The sample was a paragneiss, a natural rock, consisting of quartz, feldspare and mica. A total overlapping of the strongest quartz reflection (10i1) and the strongest mica reflection (006) is observed. Although the overlap is total with respect to $2 \theta$, it is not, if also the angle $\chi$, i.e. sample orientation, is taken into account. This is the basis of ODF analysis using superposed pole figures. The measurement of the paragneiss was performed at the Institute Max von Laue-Paul Langevin at 
Grenoble using the diffractometer D1B. With the linear position sensitive detector covering $80^{\circ}$ in $2 \theta$, the pole figures of all of the shown reflections (Figure 13) have been measured. A detailed description of the paragneiss texture will be given in another paper.

\section{DISCUSSION}

It was shown that thermal neutrons have some essential advantages for texture analysis compared with X-rays and electrons which increase particularly the possibility to analyse textures of multiphase materials. Neutron diffraction texture analysis plays an important role especially in the following problems:

- texture analysis of second phases with low volume fractions

- texture analysis of multi-phase materials with strongly different absorption coefficients for X-rays (anisotropic absorption)

- non-destructive texture determination of materials with surface coatings

- texture analysis of multi-phase materials with an inhomogeneous distribution of the components such as quartz veins within compact rock samples

As shown by Brokmeier and Bunge (1988) the texture of $1 \mathrm{Vol} . \% \mathrm{Cu}$ in an aluminium matrix could thus be determined by neutron diffraction. The $\mathrm{Cu}$ texture of the extruded sample was a weak $\langle 111\rangle$ fibre texture. As a result of the high accuracy of neutron diffraction (see Bunge, 1989) and of the relatively large sample volume it is possible to analyse textures in minority phases with much smaller volume fractions than in X-ray diffraction. Figure 14 shows for instance the diffraction pattern of an extruded aluminium sample containing $0.05 \mathrm{Vol} . \% \mathrm{Cu}$. The measurement was performed at the instrument D1B of the ILL in Grenoble with a wavelength of $0.25 \mathrm{~nm}$. Two Cu-reflections "(111) and (200)" were obtained in the measured $2 \theta$-range.

In most materials the absorption of neutrons is only a minor part of the different interactions between the neutron beam and matter. Therefore, the anisotropy in absorption as described for X-ray texture measurements of lamellar eutectic samples by Bunge 


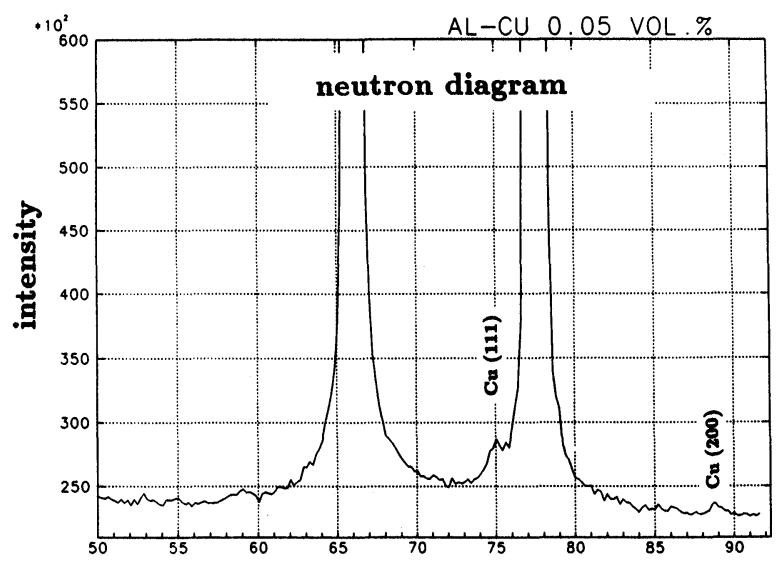

Bragg-angle $2 \theta$

Figure 14 Diffraction pattern of an Al99.95-Cu0.05 composite.

(1986b) can be neglected in the case of neutron diffraction. Hence, neutron diffraction has an essential advantage in the analysis of light element phases such as free carbon in a metallic matrix. In neutron diffraction carbon has an absorption of the same order as iron.

The advantages of neutron diffraction in texture analysis of multi-phase systems are particularly due to the new techniques described:

- measurement with a linear position detector

- peak profile analysis

- pole figure inversion with overlapping reflections

\section{Acknowledgements}

The author would like to thank the GKSS Research Center Geesthacht GmbH for the support in neutron diffraction at the Research Reactor FRG-1, the Institut Max von Laue-Paul Langevin, especially Dr. C. Ritter for the support in neutron diffraction at the instrument D1B, and to express appreciation for encouragement and helpful suggestions from Prof. H. J. Bunge. This work is funded by the German Ministry for Research and Technology (BMFT) under contract number 3BU1CLA9, and the German Research Foundation (DFG) under contract number Br961/1-1. 


\section{References}

Antoniadis, A., Berruyer, J. and Filhol, A. (1987). Affinement de spectres de diffraction de poudre par la méthode du maximum de vraisemblance ILLReport 87AN20T.

Bacon, G. E. (1975). Neutron Diffraction. Clarendon Press, Oxford.

Brockhouse, B. N. (1953). The Initial Magnetization of Nickel under Tension. Can. J. Phys. 31, 339-355.

Brokmeier, H.-G., Böcker, W. and Bunge, H.-J. (1988). Neutron Diffraction Texture Analysis in Extruded $\mathrm{Al}-\mathrm{Pb}$ Composites. Textures Microstruc. 8/9, 429-441.

Brokmeier, H.-G., Böcker, W., Dahms, M. and Bunge, H.-J. (1988). Texture of extruded $\mathrm{Al}-\mathrm{Cu}$ fibre composites. In: Mechanical and Physical Behaviour of Metallic and Ceramic Composite, p. 309-314. Ris $\varnothing$ National Lab., Roskilde (DK). Ed. S. I. Andersen, H. Lilholt and O. B. Petersen.

Brokmeier, H.-G. and Bunge, H.-J. (1988). Neutron Diffraction Texture Analysis of $1 \mathrm{Vol} . \% \mathrm{Cu}$ in Aluminium. Textures Microstruct. 10, 1-8.

Brokmeier, H.-C., Bunge, H.-J., Brehler, B., Wagner, R. and Wille, P. (1987). Texturmessungen am FRG-1 “Arbeitsbericht 1985." GKSS-Report 87/E/42.

Bunge, H.-J. (1982). Texture Analysis in Materials Science. Butterworths Publ., London.

Bunge, H. J. (1986a). Experimental Techniques In: Quantitative Texture Analysis, p. 85-128. DGM Informationsgesellschaft Oberursel. Ed. H.-J. Bunge and C. Esling.

Bunge, H. J. (1986b). Anisotropic Absorption in Multiphase Texture Analysis In: Experimental Methods of Texture Analysis, p. 395-402. DGM Informationsgesellschaft Oberursel. Ed. H.-J. Bunge.

Bunge, H.-J. (1989). This volume, 265-307.

Bunge, H.-J., Wenk, H. R. and Pannetier, J. (1982). Neutron Diffraction Texture

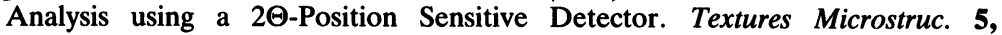
153-170.

Chadwick, J. (1932). Possible Existence of a Neutron. Nature 129, 312.

Convert, P. and Forsyth, J. B. (1983). Position Sensitive Detection of Thermal Neutrons. Academic Press, London.

Dahms, M., Brokmeier, H.-G., Seute, H. and Bunge, H.-J. (1988). Quantitative texture analysis in multiphase materials with overlapping Bragg-reflections In: Mechanical and Physical Behaviour of Metallic and Ceramic Composites, p. 327-332. Risø National Lab., Roskilde (DK). Eds. S. I. Andersen, H. Lilholt and $\mathrm{O}$. B. Petersen.

Dahms, M. and Bunge, H.-J. (1987). Texture analysis using totally and partially coincident pole figures. In Theoretical Methods of Texture Analysis, p. 143-158. DGM Informationsgesellschaft Oberursel. Ed. H.-J. Bunge.

Höfler, S., Schäfer, W. and Will, G. (1986). Texture Measurements at the Neutron Diffractometer in Jülich In: Experimental Methods of Texture Analysis, p. 241-251. DGM Informationsgesellschaft Oberursel. Ed. H.-J. Bunge.

Jansen, E., Schäfer, W. and Will, G. (1986). Application of profile analysis methods in texture measurements using position-sensitive detectors In: Experimental Methods of Texture Analysis, p. 229-240. DGM Informationsgesellschaft Oberursel. Ed. H. J. Bunge.

Kleinstück, K., Tobisch, J., Betzl, M. and Schläfer, U. (1976). Texturuntersuchung von Metallen mittels Neutronenbeugung. Krist. u. Techn. 11, 409-429. 
Smyth, J. R., Vergamini, P. J. and Schultz, A. J. (1988). Texture Analysis in Coarse-Grained Multi-Phase Rocks by Neutron Single-Crystal Diffraction In: ICOTOM, p. 801-809. TMS-AIME Warrendale, Pennsylvania. Eds. J. S. Kallend and G. Gottstein.

Szpunar, J. (1976). Atomic Energy Rev. Texture and Neutron Diffraction 14, 199-261.

Wagner, F. and Esling, C. (1986). Textures with hexagonal and trigonal crystal symmetry In: Quantitative Texture Analysis, p. 189-211. DGM Informationsgesellschaft Oberursel. Eds. H.-J. Bunge and C. Esling.

Welch, P. I. (1986). Neutron Diffraction Texture Analysis In: Experimental Methods of Texture Analysis, p. 183-207. DGM Informationsgesellschaft Oberursel. Ed. H.-J. Bunge.

Wenk, H.-R., Kern, H., Pannetier, J., Höfler, S., Schäfer, W., Will, G. and Brokmeier, H.-G. (1988). Neutron Diffraction Texture Analysis: Standard Project (Preliminary Results). In: ICOTOM, p. 229-234. TMS-AIME Warrendale, Pennsylvania. Ed. J. S. Kallend and G. Gottstein.

Will, G. (1989). This volume, 375-387. 